\title{
Recording plant status and regeneration during single visits
}

\author{
Kevin J. Walker*1, Simon J. Leach ${ }^{2}$, Christopher D. Preston ${ }^{3}$, Thomas A. Humphrey ${ }^{4}$, \\ Trevor J. James ${ }^{5}$, David A. Pearman ${ }^{6}$, Paul A. Smith ${ }^{7}$ \\ ${ }^{1}$ Botanical Society of Britain and Ireland (BSBI), Harrogate, UK; ${ }^{2}$ Taunton, UK; \\ ${ }^{3}$ Cambridge, UK; ${ }^{4}$ BSBI, Wallingford, Oxfordshire, UK; ${ }^{5}$ Ashwell, Hertfordshire, UK; \\ ${ }^{6}$ Feock, Cornwall, UK; ${ }^{7}$ Southampton, UK
}

*Corresponding author: Kevin J. Walker: kevin.walker@bsbi.org

This pdf constitutes the Version of Record published on $14^{\text {th }}$ December, 2019

\begin{abstract}
Information on the origin (status) and regeneration of plant species improves our understanding of native distributions and the establishment of non-native species. However, current categories used to record status in Britain and Ireland, whilst conceptually informative, rely on a knowledge of persistence that is impossible to assess objectively during a single (one-off) recording visit. We propose five alternative categories that focus on origin (how a species arrived at a site) rather than persistence. The first two categories apply to nationally native taxa: (1) populations that are unequivocally native and (2) those that are likely to have been introduced and/or are spreading for reasons that are obscure. The other three categories cover the occurrences of any taxon, native or non-native, that is known or suspected to have been introduced to a site: (3) introductions with unknown/obscure origins; (4) deliberate introductions; and (5) accidental introductions. For the introduced categories 3-5 we recommend that botanists also record signs of regeneration, i.e. seedlings or widely scattered patches, as a more objective measure whether a species is likely to be self-sustaining in a given locality.
\end{abstract}

Keywords: establishment; invasive; non-native; origin.

\section{Introduction}

Botanists distinguish between native species that evolved in the British Isles or arrived there naturally from a native region entirely independent of human agency, from alien species that were introduced by man, either intentionally or by accident, since the start of the Neolithic period some 6,000 years ago (Webb, 1985; Preston, 2002, 2009; Preston et al., 2002; Preston, Pearman \& Hall, 2004; Stace \& Crawley, 2015). For the New Atlas of the British and Irish flora, Botanical Society of the British Isles (BSBI) recorders were asked to assess whether native taxa were native or introduced within each 10-km grid square (hectad) in Britain and Ireland, that is to decide, using their own knowledge and experience, whether a given species could be accepted as native (Preston et al., 2002). Not all recorders complied with this request, and the patchy coverage meant that additional sources of information had 
to be used to produce the 'native' (blue) and 'alien' (red) hectad-dots depicted in the published hectad distribution maps. Problems arose for some species where views differed between adjacent vice-counties and so editorial decisions were made to iron-out these local differences and present a consistent approach (Preston et al., 2002).

For the New Atlas recorders were also asked to assess the extent to which introduced taxa were established at a given location using four categories proposed by Macpherson et al. (1996), hereafter referred to as the 'Macpherson scheme' (Macpherson, 1997): planted, a taxon which has been deliberately planted in a 'wild' situation and is not established; casual, a taxon which is briefly, i.e. for less than five years, or intermittently present; surviving, a taxon which has been present in the wild for at least five years and is neither spreading vegetatively nor reproducing effectively by seed; and established, a taxon which has been present in the wild for at least five years and is spreading clonally or effectively reproducing by seed. These four categories therefore captured information on origin, i.e. whether a taxon had been intentionally or unintentionally introduced, persistence, i.e. how long a taxon had been present, and regeneration, i.e. whether there was evidence of seed dispersal and recruitment or clonal spread. Whilst conceptually informative, however, these categories proved difficult to apply during single visits and as a result the response from BSBI recorders for the New Atlas was very patchy. In some cases, recorders were also handicapped because their records pre-dated the Macpherson scheme or because there was no option to capture status information within recording software they were using. Due to these problems, many recorders developed their own schemes or gave up recording status altogether.

In the absence of clear guidance, the recording of status has largely been ignored by British and Irish botanists since the publication of the New Atlas in 2002. This has led to difficulties in producing native range maps and in analysing trends over time as well as reducing the potential value of BSBI records for research into the impacts (and control) of invasive non-native species (INNS) which have become a major focus of government environmental policy (Defra, 2015). Here we discuss some of the limitations of the Macpherson scheme and present alternative status categories designed for routine botanical recording, namely single (one-off) visits to record species present within sites or grid squares. Plant nomenclature follows Stace (2019).

\section{Limitations of the Macpherson scheme for routine botanical recording}

The Macpherson categories are difficult to use during single visits for two main reasons. First, Macpherson et al. (1996) defined a 'casual' taxon as a non-native plant species that had been unintentionally introduced, usually amongst raw materials (seed, waste, soil), that ultimately fails to persist (beyond five years) due to a lack of regeneration. From a population perspective, this means that they have a growth rate (or lambda) ${ }^{1}$ of less than 1 and therefore rely on repeated introduction by humans to persist within an area (Stace \& Crawley, 2015). Conversely an 'established' taxon is one that has been present in the wild for over five years and is self-regenerating effectively i.e. it has a population growth rate (lambda) of greater

\footnotetext{
${ }^{1}$ Lambda is defined as the ratio of population size at the end of one time interval to population size at the end of the previous time interval expressed as $\mathrm{N}(\mathrm{t}+1) / \mathrm{N}(\mathrm{t})$ where $\mathrm{N}$ is the number of individuals and $\mathrm{t}$ is the first time interval.
} 
than 1. However, the field botanist seldom knows how long a taxon has been present at a particular site or can predict how long it will persist without repeated observations over many years. Even if offspring are present and can be identified (i.e. seedlings, juveniles) they do not, on their own, demonstrate that a species will persist as even casuals can produce abundant offspring under certain conditions. The second main issue with the Macpherson categories is that there is no clear distinction between 'casuals' and 'survivors' from a population perspective as both share a growth rate close to zero (i.e. a lambda of $<1$ ) and are therefore unlikely to survive beyond a few generations. The only clear distinction is their longevity: casuals are usually short-lived (annuals, biennials, short-lived perennials) whereas survivors tend to be perennials which can persist for many decades (or even centuries in the case of trees) without producing offspring.

\section{Alternative status categories}

We propose five categories for the recording of plant status during single visits that rely on an assessment of origin rather than persistence (Table 1). These categories can be used for any plant taxon found growing in wild locations, i.e. growing in any habitat occurring up to and including the boundaries of residential properties but excluding agricultural crops (Walker et al., 2016). The proposed categories therefore cover species planted for a wide range of purposes including ornament, amenity, landscaping, soil soil/sand stabilisation, and habitat or species conservation or restoration (Table 2 ). The first two categories apply exclusively to nationally native taxa ${ }^{2}$ whereas categories 3-5 apply to introductions regardless of whether they are nationally native or non-native.

Table 1. Categories for assigning status to occurrences of plant species during single visits.

\begin{tabular}{|l|c|l|}
\hline Category & Code & Description \\
\hline 1. Native & N & $\begin{array}{l}\text { A nationally native } \text { taxon which is by default thought } \\
\text { to be native in a locality. }\end{array}$ \\
\hline $\begin{array}{l}\text { 2. Native, origin } \\
\text { unknown }\end{array}$ & NA & $\begin{array}{l}\text { A nationally native taxon suspected of having been } \\
\text { introduced in an area where it is by default thought } \\
\text { to be native or spreading from an area where it is } \\
\text { native. This includes taxa that are spreading along } \\
\text { transport corridors or recent colonists that could } \\
\text { conceivably have spread from areas where they are } \\
\text { native such as European orchids with no direct } \\
\text { evidence of planting (e.g. Serapias lingua). }\end{array}$ \\
\hline $\begin{array}{l}\text { 3. Introduced, } \\
\text { origin unknown }\end{array}$ & I & $\begin{array}{l}\text { Any taxon known or suspected of having been } \\
\text { introduced to a locality where the origin and/or the } \\
\text { mechanism by which it arrived is unknown. }\end{array}$ \\
\hline $\begin{array}{l}\text { 4. Intentionally } \\
\text { introduced }\end{array}$ & $\mathrm{P}$ & $\begin{array}{l}\text { Any taxon deliberately planted in the wild or likely to } \\
\text { have been given its location and physical setting. }\end{array}$ \\
\hline $\begin{array}{l}\text { 5. Accidentally } \\
\text { introduced }\end{array}$ & $\mathrm{A}$ & $\begin{array}{l}\text { Any taxon accidentally introduced to the wild or likely } \\
\text { to have been given its location and physical setting. }\end{array}$ \\
\hline
\end{tabular}

\footnotetext{
${ }^{2}$ By nationally native we are referring to their status within Great Britain and Ireland taken as a whole but they could equally be applied to GB and Ireland separately.
} 


\section{Native $(N)$}

The default category for native species, i.e. the occurrence of a nationally native taxon within a location where it is assumed to be native (sensu Preston et al., 2002) and where there is no reason to doubt this assessment. By native we mean in the absence of direct human influence although admittedly there will be grey areas where human activities are unwittingly influencing the spread of some nationally native species, for example roadside halophytes (see next section and Discussion). If there is any appreciable doubt as to the status of a native species within a given locality where it is by default thought to be native, then the record should be placed under the next category.

Table 2. The main habitats outside of private gardens where native and nonnative plant species are likely to be introduced or are spreading with human assistance.

\begin{tabular}{|l|l|}
\hline Category & Habitat \\
\hline Transport & $\begin{array}{l}\text { Road and motorway embankments } \\
\text { Salted road verges }\end{array}$ \\
\hline Urban / suburban & $\begin{array}{l}\text { Public parks and amenity areas } \\
\text { Greenspace and urban plantings } \\
\text { Wildlife parks, conservation areas and local nature reserves } \\
\text { Golf courses }\end{array}$ \\
\hline Agricultural & $\begin{array}{l}\text { Game cover } \\
\text { Wildlife strips } \\
\text { Habitat creation and restoration } \\
\text { Farm woodlands } \\
\text { Hedgerows } \\
\text { Crops including biomass/biofuel }\end{array}$ \\
\hline Extractive/energy & $\begin{array}{l}\text { Landscaped areas of abandoned mines and quarries } \\
\text { Settling ponds near power stations }\end{array}$ \\
\hline Forestry & $\begin{array}{l}\text { Commercial forestry plantations } \\
\text { Ornamental woodlands } \\
\text { Shelter-belts }\end{array}$ \\
\hline Standing waters & $\begin{array}{l}\text { Ornamental water bodies (ponds, lakes, etc.) } \\
\text { Artificial water-bodies associated with water drainage, } \\
\text { treatment and supply (e.g. construction/settling ponds, } \\
\text { waterworks, drainage ponds raised reservoirs) } \\
\text { Waters managed by anglers and freshwater fish farms }\end{array}$ \\
\hline Conservation & $\begin{array}{l}\text { Habitat creation, recreation and restoration } \\
\text { Species introductions and translocations } \\
\text { Experimental introductions } \\
\text { Introductions by private individuals and groups motivated by } \\
\text { conservation considerations }\end{array}$ \\
\hline Dune / sea defence stabilisation \\
\hline
\end{tabular}

2. Origin unknown (NA)

The occurrence of a nationally native taxon in an area where it is assumed to be native (sensu Preston et al., 2002) but is suspected of having been introduced, or is 
known to have spread there naturally from a presumed introduced population nearby (e.g. waterborne dispersal during floods). This category will include all occurrences of a nationally native taxon in an area where the evidence for it being native is inconclusive (e.g. Acer campestre in parts of Scotland and Ireland). We are also of the view that it should include al/ records of native species that appear to be spreading (or have spread), apparently without direct human assistance, into habitats created by man, including possibly most controversially, records of coastal halophytes that occur on salted roadsides inland (Atriplex littoralis, Cochlearia danica, Puccinellia distans, Sagina maritima, Spergularia marina). By the same token it could include ecotypes of common inland species that are invading the same niche (e.g. salt tolerant varieties of Elymus repens). Leach (2003) argued that these occurrences should be treated as natural extensions of native ranges, or possibly 'native or alien' (NA), whereas the editors of the New Atlas treated all inland records of some halophytes on roadsides as introductions. For pragmatic reasons, we suggest that such occurrences should be treated under this category so that they can continue to be differentiated from natural (coastal) populations and long-known and certainly native occurrences of halophytes on inland salt marshes, brine springs (Lee, 1975, 1977) or the upper tidal reaches of major rivers. Other examples might include Phragmites australis growing in recently created wetlands or 'native wildflowers' on roadside embankments for which natural colonisation cannot be ruled out. Ideally a comment should be attached to each record stating why there is reason to doubt it being native and noting the likely origin.

\section{Species introduced by humans but whose origin is unclear (I)}

The occurrence of a nationally native or non-native taxon that is known or suspected to have been introduced to a location but where the origin is not known or obscure. We suspect that this category will apply to the vast majority of plants introduced to wild locations.

\section{Species intentionally introduced by humans $(P)$}

The occurrence of a nationally native or non-native taxon that has been deliberately planted in a wild location. In a minority of instances there will be definitive proof that a plant has been introduced for example when they are growing in newly planted woodlands or areas sown with wildflower mixtures or game cover. However, for most introductions the planted origin will have to be inferred from the physical setting, associated vegetation and the recorder's knowledge of the species or site. Examples include daffodils or 'wildflowers' that have been planted on roadsides but are now regenerating and therefore having the appearance of being wild.

\section{Species accidentally introduced by humans $(A)$}

The occurrence of a nationally native or non-native taxon that has been introduced accidentally by human activities. Most accidental introductions arrive as contaminants or constituents of spilled or outcast seed, soil, raw materials (e.g. compost, gravel, sand, wools and fibres, etc.), garden waste (throw-outs) or simply as escapes from ornamental plantings. Accidental introductions from spilled seed are usually found close to bird-feeders in gardens (e.g. Guizotia abyssinica) and woods managed for gamebirds whereas seed contaminants usually occur on or near agricultural land where seed has been spilled or sown (e.g. roadsides, arable fields, 
game cover strips). Contaminants in raw materials (soil, sand, rock, gravel/chippings) are associated with a wide range of activities including transport, construction, agriculture, horticulture, forestry, shipping and road/track surfacing. In the past by-products of the wool industry, such as esparto and shoddy, were the main pathways for many aliens, usually in areas where they were offloaded (docks, railway sidings), cleaned (riverbanks downstream of mills) and used to fertilise and improve the soil structure of cultivated fields (shoddy fields) although such incidences are now rare due to a decline in the use of such by-products (Shimwell, 2006). Human and agricultural waste (food, sewage) is also an important pathway for many culinary species such as Solanum lycopersicum. In contrast, most ornamental introductions often arise accidentally from garden waste discarded on roadsides, wood margins and land adjacent to gardens. In comparison to seed/raw material contaminants, which are by and large annuals, garden throw-outs tend to be perennials that reproduce vigorously from vegetative organs (rhizomes, root fragments, bulbils, etc.) and can therefore persist for long periods without spreading or producing offspring.

\section{Recording evidence of regeneration}

In order to improve our understanding of establishment of non-native species we recommend that recorders also note any observed regeneration under categories 35 where the evidence is clear and unequivocal i.e. where offspring occur including vegetative (clonal) spread to form multiple patches. However, we do not recommend that recorders use the term 'not regenerating' because the absence of offspring during a single visit is not conclusive proof that regeneration is not occurring. For example, widely planted conifers such as Picea sitchensis may not appear to be regenerating locally but might be producing seedlings well away from plantations on open moorland or mountain slopes (Ison \& Braithwaite, 2009).

It is likely that almost all occurrences of well naturalised aliens would be assigned to this category, for example Acer pseudoplatanus and Marticaria discoidea, as well as ones known to be negatively impacting native species through direct competition, such as Heracleum mantegazzianum, Impatiens glandulifera, Lysichiton americanus, and Rhododendron spp. All of these regenerate almost exclusively by seed whereas invasive species regenerating prolifically by vegetative means include Allium paradoxum, Cardamine bulbifera (non-native populations), Carpobrotus edulis, Crassula helmsii, Fallopia japonica and Hydrocotyle ranunculoides.

\section{Discussion}

The new status categories described in this paper differ from the Macpherson scheme in three important respects: first, they incorporate the uncertainty over the origin of many species encountered in modern, human-modified landscapes; second, they remove the need to assess the persistence of a species during a single visit; and third, they provide recorders with the option to capture information on regeneration. We therefore hope that botanists will find these categories more straightforward and rewarding to use in the field although we acknowledge that many difficulties remain, some of which are discussed below. 


\section{Problem species}

Without exception, British and Irish habitats have been modified by human activity, more or less, over recent millenia. From a botanical perspective possibly the most significant has been the planting of native wildflowers, shrubs and trees for amenity, ornamental, landscaping and conservation purposes which has served to blur the native ranges of many species (Dines, 2016). For the New Atlas, significant work was required to distinguish between presumed-native and presumed-alien occurrences (at the hectad level) for around 100 native plants species that had been widely planted whereas for around a dozen this was not practical and so all records were mapped as if they were native (e.g. Chamerion angustifolium, Dipsacus fullonum, Quercus robur). In addition, there were a number of native species that appeared to have expanded their ranges 'naturally' since the 1960s in response to human activity, most notably coastal halophytes that had spread inland along roadsides affected by salt spray (e.g. Atriplex littoralis, Cochlearia danica, Puccinellia maritima, Spergularia marina). Most of these occurrences were treated as 'alien' in the New Atlas while other (non-coastal) natives colonising the same habitat, presumably in the same way, were treated as 'native' (Leach, 2003). The difficulty in differentiating between 'natural' and clearly human-influenced occurrences for such species is likely to increase further due to the increasing influence of humanmediated environmental change on species' distributions (Preston, 2009). Indeed, a number of southerly distributed species appear to spreading northwards possibly as a result of increasing temperatures (e.g. Crassula tillaea, Dactylorhiza praetermissa, Ophrys apifera, Poa infirma). Assigning status to populations of these species in new areas has often proven problematic due to uncertainties over their origin. We therefore recommend that wherever possible recorders attempt to distinguish between human-assisted and 'presumed-natural' species-occurrences using the categories outlined above or, where there is doubt, categorise them as of 'unknown origin' so they can be differentiated from unequivocally native populations.

\section{Regeneration}

Many non-native species are now an intrinsic part of our wild flora but currently we know very little about how they regenerate and spread. The recording of regeneration as an additional status attribute therefore will help to improve our understanding of how non-native species are behaving and potentially help us predict which species are likely to increase in abundance and potentially become problems in the future. However, the recording of regeneration during single visits, it is not without its problems. Seedlings and juveniles of most species are often difficult to detect and identify, especially when they occur in the absence of parents, or are missed altogether if the survey takes place prior to germination.

Consequently, most botanists ignore juvenile plants when out recording. Conversely, species producing large numbers of easily identifiable seedlings may flatter to deceive, ultimately failing to persist in the longer-term due to adverse climatic conditions, lack of disturbance, herbivory or competition. In such cases the degree of establishment will tend to be overestimated, for example the apparently well-established colonies of Pistia stratiotes in the Bridgwater-Taunton Canal (v.c.5) which were killed off during cold winters. A more fundamental problem perhaps is how to assess taxa that are regenerating by clonal spread. We would suggest that clonal species are only categorised as regenerating (as above) if they are clearly 
forming multiple patches (new ramets) by the dispersal of vegetative propagules (e.g. bulbils, turions and plantlets, stem or root fragments).

\section{Combining national and local views}

An accurate assessment of the naturalisation status of a species in a locality often requires both a national overview of the history and ecology of the species and a knowledge of the local situation. For example, a local observer may not question the native status of a species where it occurs mainly in semi-natural habitats whereas in surrounding areas it may be more obviously planted. Central editors have the privilege of having access to these multiple local views on which to make a more well-informed decision. In assessing status, therefore both local recorders and central editors have a role to play, and we should aim in the future to have recording methods and software which makes this information easier to capture and share.

\section{Conclusion}

The proposed scheme is designed to improve the accuracy or recording plant status by removing the need for recorders to make assumptions about persistence during single visits. The scheme also allows for uncertainty where the origin of a plant is obscure. We therefore hope that botanists will find the scheme more workable than its predecessors and that its widespread uptake will help BSBI to more effectively map native distributions and provide important insights into the introduction pathways, establishment and impacts of many non-native species. The need to improve our understanding in this area is becoming increasingly important as native ranges are further eroded by human activity and the impacts of many introduced plant taxa continue to grow.

\section{Acknowledgements}

We thank Mick Crawley for his comments on an earlier draft of this paper and to members of the BSBI's Records and Research Committee for their expert advice and guidance throughout the development of this guidance.

\section{References}

Defra 2015. The Great Britain non-native species strategy. London: Department of Food and Rural Affairs, Scottish Government \& Welsh Government, HMSO. Dines, T. 2016. Keeping the wild in wildflower. British Wildlife 28: 112-117. Ison, J. \& Braithwaite, M.E. 2009. The status of some alien trees and shrubs in Britain. London: Botanical Society of the British Isles.

Leach, S.J. 2003. Roadside halophytes and the native/alien conundrum. BSBI News 93: $18-20$.

Lee, J.A. 1975. The conservation of British inland salt marshes. Biological Conservation 8: 143-151.

Lee, J.A. 1977. The vegetation of British inland salt marshes. Journal of Ecology 65 : 673-698.

Macpherson, P. 1997. Plant status nomenclature and Atlas 2000. BSBI News 77: 7-8. Macpherson, P., Dickson, J.H., Ellis, R.G., Kent, D.H. \& Stace, C.A. 1996. Plant status nomenclature. BSBI News 72: 13-16. 
Preston, C.D. 2002. Approaches to native and alien species. Transactions of the Suffolk Naturalists' Society 38: 37-48.

Preston, C.D. 2009. The terms 'native' and 'alien' - a biogeographical perspective. Progress in Human Geography 33: 702-713.

Preston, C.D., Pearman, D.A. \& Dines, T.D. (eds. \& comps.) 2002. New atlas of the British and Irish flora. Oxford: Oxford University Press.

Preston, C.D., Pearman, D.A. \& Hall, A.R. 2004. Archaeophytes in Britain. Biological Journal of the Linnaean Society 145: 257-294.

Shimwell, D.W. 2006. A shoddy tale: perspectives on the wool alien flora in West Yorkshire in the twenty-first century. Watsonia 26: 127-137.

Stace, C.A. 2019. New flora of the British Isles. $4^{\text {th }}$. ed. Middlewood Green, Suffolk: C\&M Floristics.

Stace, C.A. \& Crawley, M.J. 2015. Alien plants. London: William Collins.

Walker, K.J., Pearman, D.A. \& Stroh, P. 2016. Where and what do we record? BSBI News 133: 35.

Webb, D.A. 1985. What are the criteria for presuming native status? Watsonia 15: $\underline{231-23 .}$.

Copyright retained by author(s). Published by BSBI under the terms of the Creative Commons Attribution 4.0 International Public License.

ISSN: $2632-4970$

https://doi.org/10.33928/bib.2019.01.283 